\title{
A Combined Study of New Escape Time Fractal for Sine and Inverse Tangent Functions
}

\author{
Shashank Lingwal \\ Research Scholar \\ Dept. of Computer Science and \\ Applications \\ G.B.Pant Engineering College, \\ Pauri Garhwal, India
}

\author{
Ashish Negi \\ Associate Professor \\ Dept. of Computer Science and \\ Applications \\ G.B.Pant Engineering College, \\ Pauri Garhwal, India
}

\author{
Y. S. Chauhan \\ Assistant Professor \\ Dept. of Computer Science and \\ Applications \\ G.B.Pant Engineering College, \\ Pauri Garhwal, India
}

\begin{abstract}
Complex graphics of dynamical system have been a subject of intense research nowadays. The fractal geometry is the base of these beautiful graphical images. Many researchers and authors have worked to study the complex nature of the two most popular sets in fractal geometry, the Julia set and the Mandelbrot set, and proposed their work in various forms using existing tools and techniques. The generation of fractals and study of the dynamics of transcendental function is one of the emerging and interesting fields of research nowadays. Recently, Ashish Negi, Rajeshri Rana and Yashwant S. Chauhan are among those researchers who have contributed a lot in the area of Fractal Geometry applications. In this paper we review the recently done work on sine and inverse tangent functions.
\end{abstract}

\section{Keywords}

Fractals, Relative Superior Mandelbrot Set, Relative Superior Julia Set, Ishikawa Iteration.

\section{INTRODUCTION}

In 1918, French mathematician Gaston Julia [12] investigated the iteration process of complex function and attained a Julia set, which is a landmark in the field of fractal theory. The object Mandelbrot set on the other hand was given by Benoit B. Mandelbrot [14] in 1979. The visual complexity, beauty and self-similarity of these structures have made these subjects of a wide area of intense research right from its advent. The various extensions and variants of both of these sets have been extensively studied using Picard's iterations. We have applied in this research article a new iteration process called Ishikawa iteration.

Fractals are mathematical fireworks thriving on the new horizons of research in modern analysis and computers. Fractal theory is an exciting branch of mathematical sciences, whose mere existence have worried the founders of modern analysis and so in recent more sympathetic light has been shed on these entities. They can be a geometrical representation of ubiquitous natural objects like clouds, rivers and forests. These all are fractals in nature and can be modeled on a computer using a recursive algorithm of computer graphics.

In this paper we studied and reviled the dynamical behavior of inverse tangent function also termed as arc tangent function, along with the sine function, which falls under the category of transcendental functions. Fixed points are determined using relative superior Ishikawa iterates to develop an entirely new class of fractal images for these functions. Escape criteria of polynomials are used to generate relative superior Mandelbrot sets and relative superior Julia sets.

The study of dynamical behavior of the transcendental function were initiated by Fatou[10]. For transcendental function, points with unbounded orbits are not in Fatou sets but they must lie in Julia sets. Attractive points of a function have a basin of attraction, which may be disconnected. A point $\mathrm{z}$ in Julia for cosine function has an orbit that satisfies $|\operatorname{Im} z|>=50$.

A Julia set thus, satisfies the following properties:

(i) Closed

(ii) Nonempty

(iii) Forward invariant $t$ (If $\mathrm{z} J(F)$ ), then $F(z) J(F)$, where $F$ is the function

(iv) Backward invariant

(v) Equal to the closure of the set of repelling cycles of F.

\section{ELABORATION OF CONCEPTS INVOLVED}

\subsection{Mandelbrot Set:}

Definition 1. The Mandelbrot set $M$ for the quadratic $Q_{C}(z)=\mathrm{z}^{2}+\mathrm{c}$ is defined as the collection of all $c \in C$ for which the orbit of point 0 is bounded, that is, $M=\left\{c \in C:\left\{Q_{c}^{n}(O)\right\} ; n=0,1,2,3 \ldots\right.$ is bounded $\}$

An equivalent formulation is

$$
M=\left\{c \in C:\left\{Q_{c}^{n}(0) \text { does not tends to } \infty \text { as } n \rightarrow \infty\right\}\right\}
$$

We choose the initial point 0 , as 0 is the only critical point of $\mathrm{Q}_{\mathrm{c}}$.

\subsection{Julia Set:}

Definition 2. The set of points $\mathrm{K}$ whose orbits are bounded under the iteration function of $\mathrm{Q}_{\mathrm{c}}(\mathrm{z})$ is called the Julia set. We choose the initial point 0 , as 0 is the only critical point of $\mathrm{Q}_{\mathrm{c}}(\mathrm{z})$.

\subsection{Ishikawa Iteration:}

Definition 3. Ishikawa Iterates $[11,13,16]$ : Let $X$ be a subset of real or complex number and $f: X \rightarrow X$ for 
all $x_{0} \in X$, we have the sequence $\{x n\}$ and $\{y n\}$ in $X$ in the following manner:

$y_{n}=S^{\prime}{ }_{n} f\left(x_{n}\right)+\left(1-S^{\prime}{ }_{n}\right) x_{n}$

$x_{n+1}=S_{n} f\left(y_{n}\right)+\left(1-S_{n}\right) x_{n}$

Where $0 \leq S^{\prime}{ }_{n} \leq 1, \quad 0 \leq S_{n} \leq 1$ and $S^{\prime}{ }_{n} \& S_{n}$ are both convergent to non-zero number.

\subsection{Relative Superior Orbit:}

Definition 4. [13] The sequence $x_{n}$ and $y_{n}$ constructed above is called Ishikawa sequence of iteration or relative superior sequence of iterates. We denote it by $\operatorname{RSO}\left(x_{0}, s_{n}, s_{n}{ }_{n}, t\right)$.

Notice that $\operatorname{RSO}\left(x_{0}, s_{n}, s_{n}{ }_{n}, t\right)$ with $s_{n}{ }_{n}=1$ is $S O\left(x_{0}, s_{n}, t\right)$ i.e. Mann's orbit and if we place $s_{n}=s_{n}^{\prime}=1 \quad$ then $\quad R S O\left(x_{0}, s_{n}, s_{n}^{\prime}, t\right) \quad$ reduce to $O\left(x_{0}, t\right)$

We remark that Ishikawa orbit $R S O\left(x_{0}, s_{n}, s_{n}{ }_{n}, t\right)$ with $s_{n}{ }_{n}=1 / 2$ is relative superior orbit.

\subsection{Relative Superior Mandelbrot Set :}

Now we define Mandelbrot set for the function with respect to Ishikawa iterates. We call them as Relative Superior Mandelbrot sets.

Definition 5. [13] Relative Superior Mandelbrot set RSM for the function of the form $Q_{c}(z)=z^{n}+c$, where $\mathrm{n}=$ $1,2,3, \ldots$ is defined as the collection of $c \in C$ for which the orbit of 0 is bounded i.e. $R S M=\left\{c \in C: Q_{c}^{k}(0): k=0,1,2,3 \ldots\right\}$ is bounded.

In functional dynamics, we have existence of two different types of points. Points that leave the interval after a finite number are in stable set of infinity. Points that never leave the interval after any number of iterations have bounded orbits So, an orbit is bounded if there exists a positive real number.

\subsection{Relative Superior Julia Set :}

Definition 6. [2] The set of points RSK whose orbits are bounded under relative superior iteration of function $\mathrm{Q}(\mathrm{z})$ is called Relative Superior Julia sets. Relative Superior Julia set of Q is boundary of Julia set RSK.

\section{ESCAPE CRITERION FOR RELATIVE SUPERIOR JULIA AND MANDELBROT SET}

\subsection{Escape Criterion for Quadratics:}

[13] Suppose that $|z|>\max \left\{|c|, 2 / s, 2 / s^{\prime}\right\}$, then $\left|z_{n}\right|>(1+\lambda)^{n}|z|$ and $|z| \rightarrow \infty$ as $n \rightarrow \infty$. So, $|z| \geq|c|$ and $|z|>2 / s$ as well as $|z|>2 / s^{\prime}$ shows the escape criteria for quadratics.

\subsection{Escape Criterion for Cubic:}

[13] Suppose,

$|z|>\max \left\{|b|,(|a|+2 / s)^{1 / 2},\left(|a|+2 / s^{\prime}\right)^{1 / 2}\right\} \quad$ then $\left|z_{n}\right| \rightarrow \infty$ as $n \rightarrow \infty$. This gives the escape criterion for cubic polynomials.

\subsection{General Escape Criterion:}

[13] Consider $|z|>\max \left\{|c|,(2 / s)^{1 / 2},\left(2 / s^{\prime}\right)^{1 / 2}\right\}$ then $\left|z_{n}\right| \rightarrow \infty$ as $n \rightarrow \infty$ is the escape criterion.

Note that the initial value $\mathrm{z}_{0}$ should be infinity, since infinity is the critical point of $z \rightarrow\left(z^{n}+c\right)^{-1}$. However, instead of starting with $\mathrm{z}_{0}=$ infinity, it is simpler to start with $\mathrm{z}_{1}=\mathrm{c}$, which yields the same result. A critical point of $z \rightarrow F(z)+c$ is a point where $F^{\prime}(z)=0$.

\section{SIMULATIONS AND RESULTS}

\subsection{Generation of relative superior} Mandelbrot Set (Sine Quad. function)

Fig.1 : Relative Superior Mandelbrot Set for $s=s^{\prime}=1$

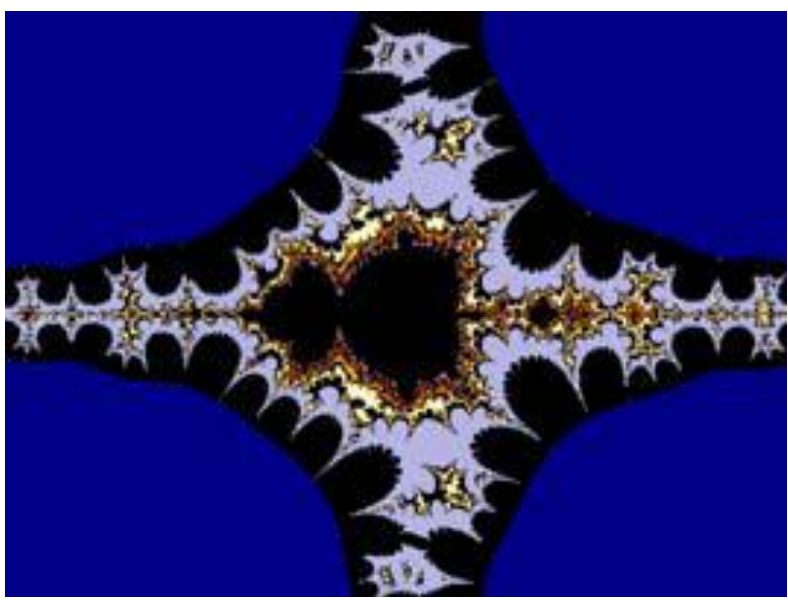

Fig.2 : Relative Superior Mandelbrot Set for $s=0.3, s^{\prime}=0.7$

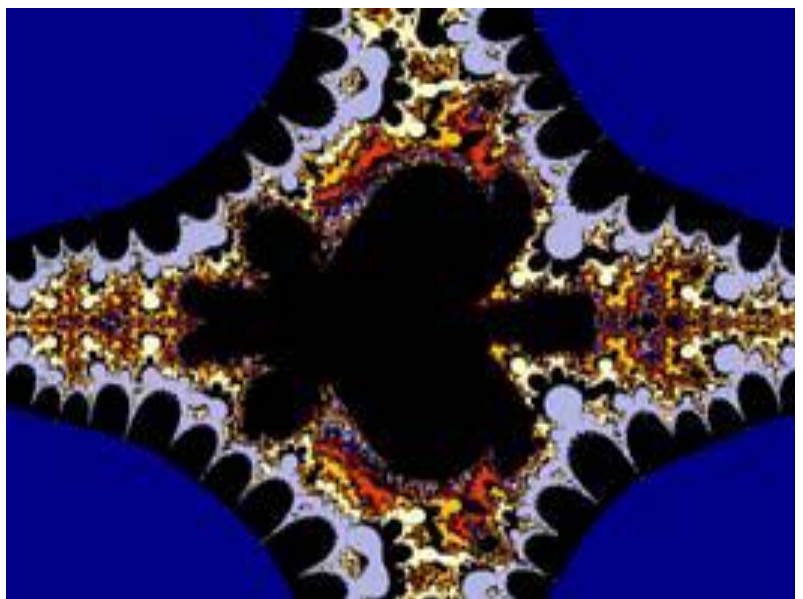




\subsection{Generation of relative superior} Mandelbrot Set (Sine Cubic function)

Fig.3 : Relative Superior Mandelbrot Set for $s=s^{\prime}=1$

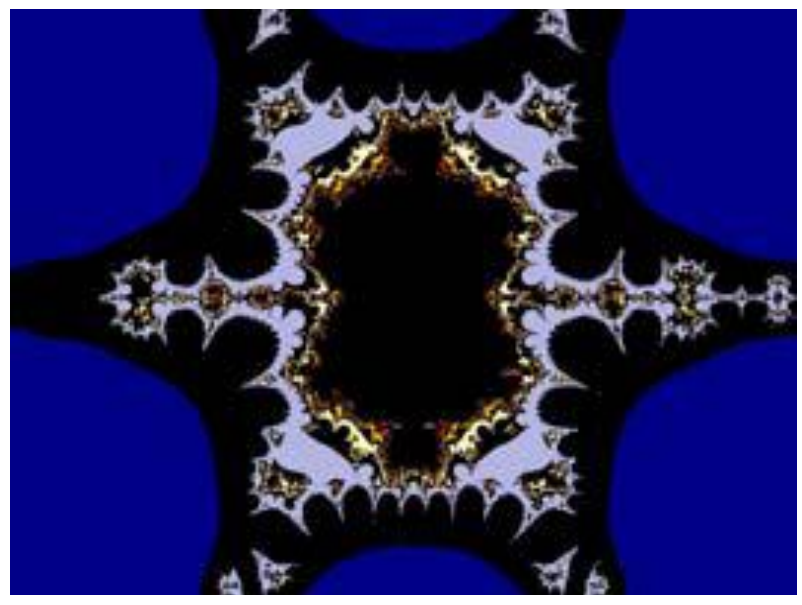

Fig.4 : Relative Superior Mandelbrot Set for $s=0.3, s^{\prime}=0.7$

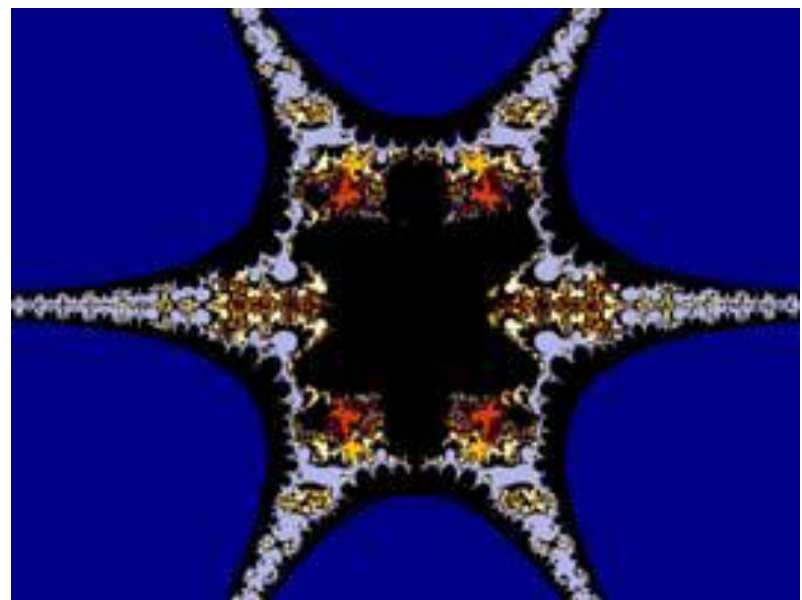

4.3 Generation of relative superior Mandelbrot Set (Tangent Quad. function)

Fig.5 : Relative Superior Mandelbrot Set for $s=s^{\prime}=1$

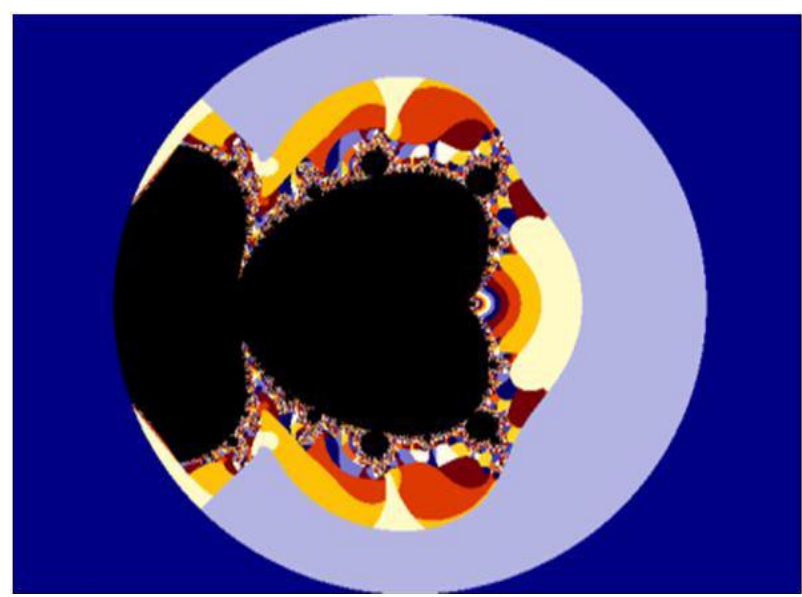

Fig.6 : Relative Superior Mandelbrot Set for $s=0.9, s^{\prime}=0.1$

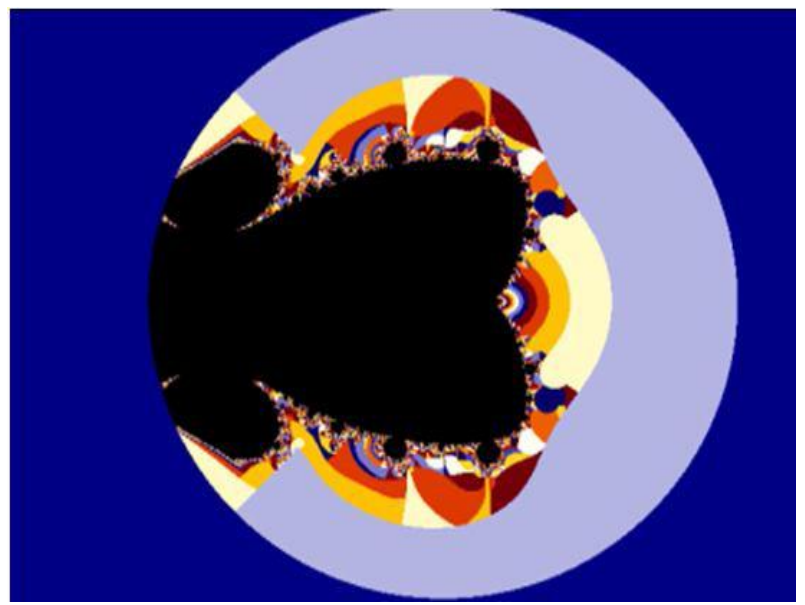

4.4 Generation of relative superior Mandelbrot Set (Tangent Cubic function)

Fig.7 : Relative Superior Mandelbrot Set for $s=s^{\prime}=1$

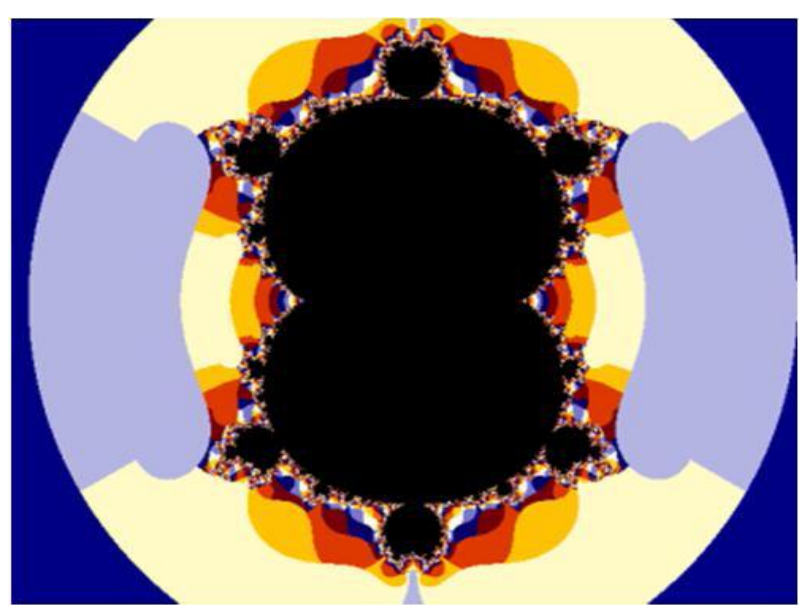

Fig.8 : Relative Superior Mandelbrot Set for $s=0.9, s^{\prime}=0.1$

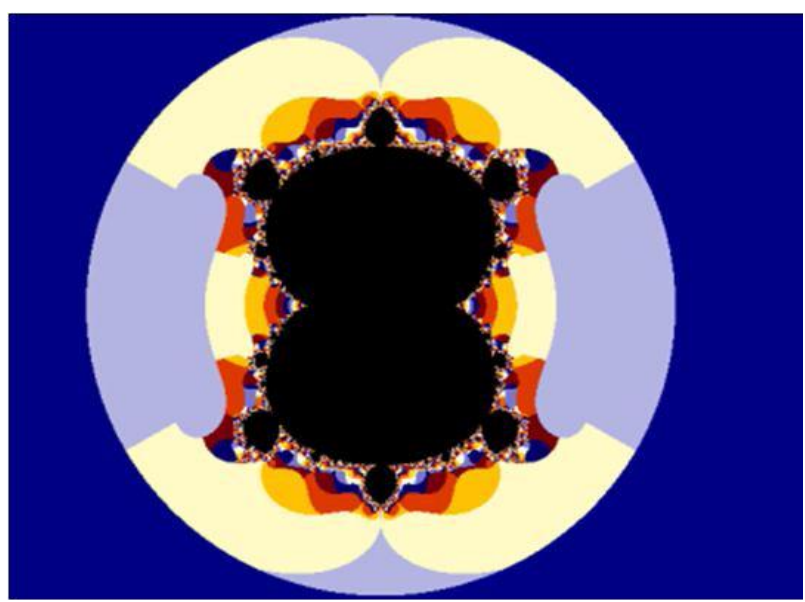




\subsection{Generalization of relative superior}

\section{Mandelbrot Set}

Fig.9 : Relative Superior Mandelbrot Set for $s=0.1, s^{\prime}=0.5$ $\mathrm{n}=19$

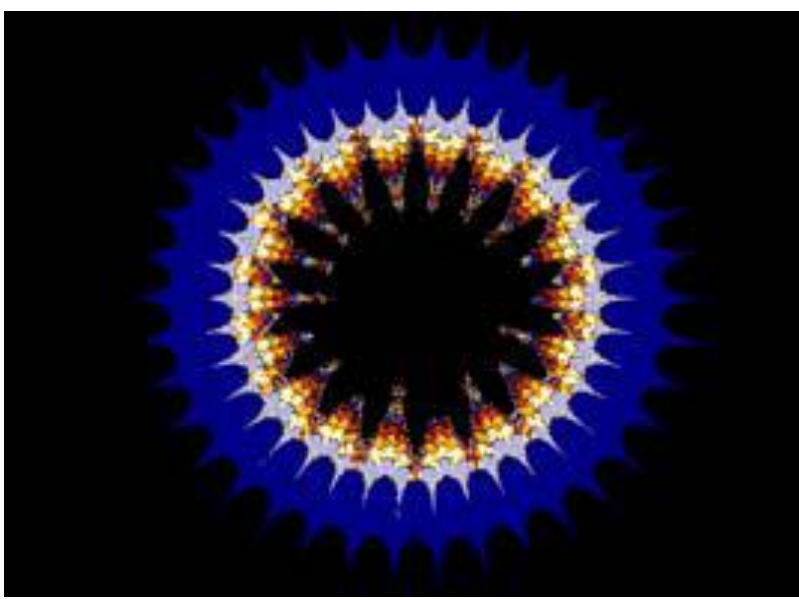

\subsection{Generation of relative superior Julia} sets

Fig.10 : Relative Superior Julia Set(Sine Quad. function) for $s=0.3, s^{\prime}=0.7 \mathrm{c}=-\mathbf{0 . 1 8 4 8 4 2 5 6 5 1 + 0 . 2 4 5 3 5 1 4 2 7 3 i}$

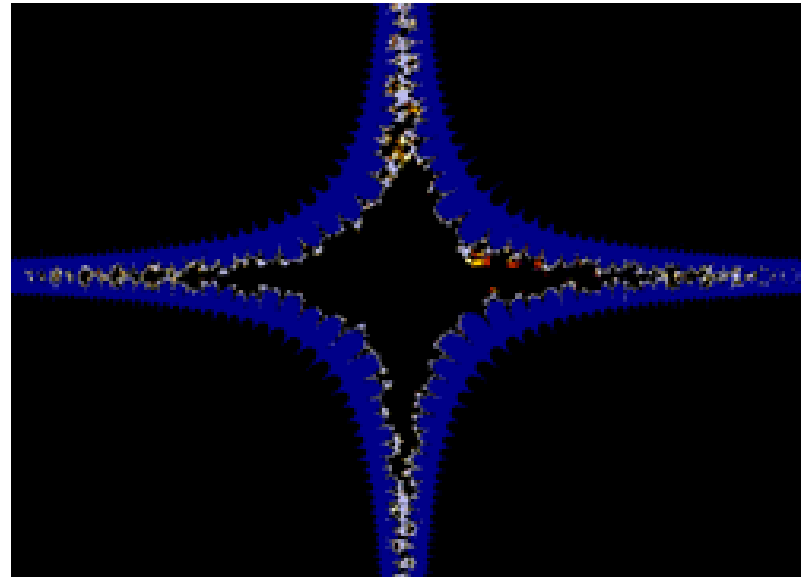

Fig.10 : Relative Superior Julia Set (Sine Cubic Function) for $s=0.3, s^{\prime}=0.7 c=0.06553079165+1.052110021 i$

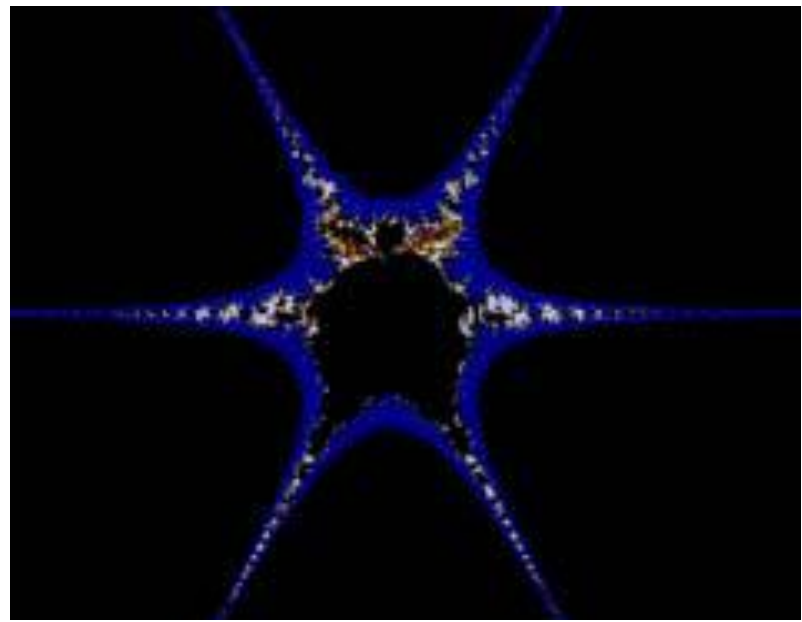

Fig.11 : Relative Superior Julia Set (Tangent Quad. Function) for $s=0.6, s^{\prime}=0.3, c=-$ $0.61455061980+0.00900541716 \mathrm{i}$

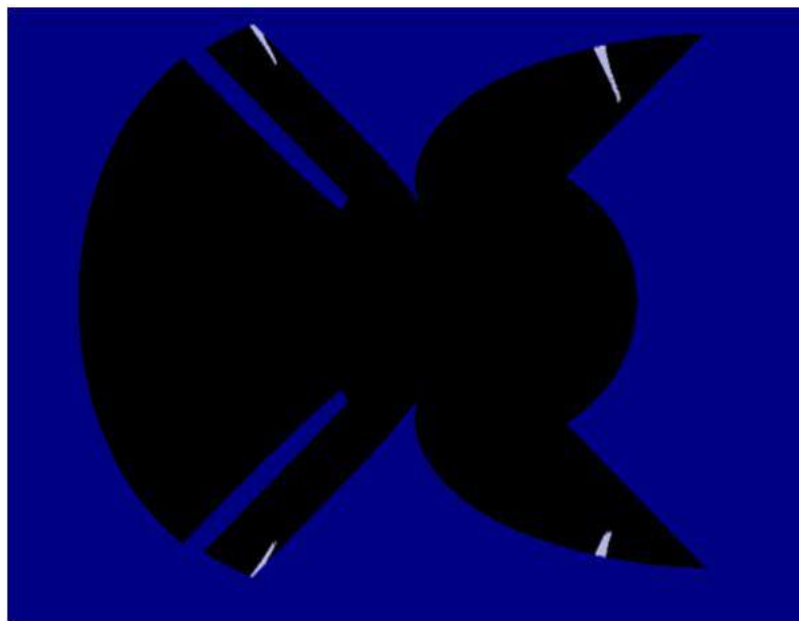

Fig.12 : Relative Superior Julia Set (Tangent Cubic Function) for $\mathrm{s}^{=0.9}, \mathrm{~s}^{\prime}=0.1, \mathrm{c}=-\mathbf{0 . 0 3 3 5 2 1 8 4 2 3 9}$ -

\section{$0.03135431148 i$}

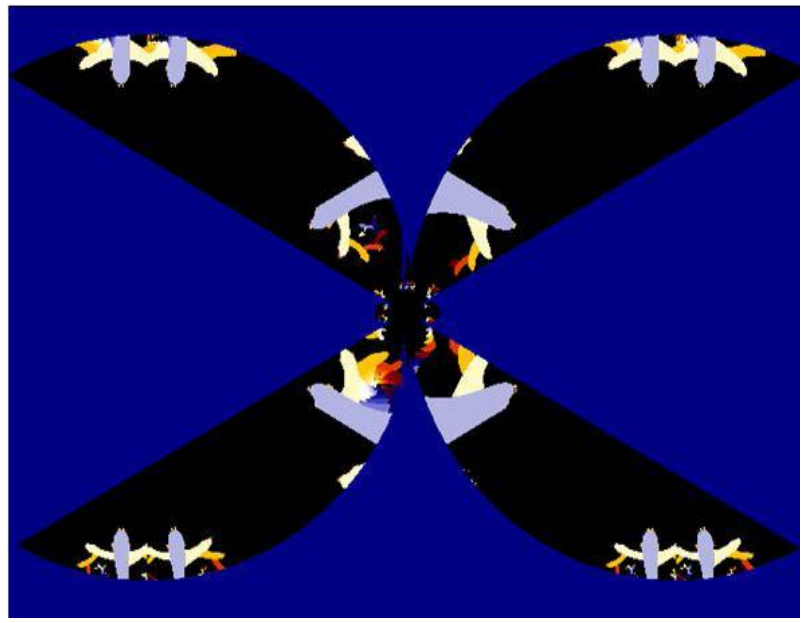

\subsection{Fixed Point Calculations}

Table 1. Fixed points of Sine quadratic polynomial, Orbit of $F(z)$ at $s=0.1$ and $s^{\prime}=0.5$ for $(\mathrm{z0}=3934870291+0 i)$

\begin{tabular}{|c|c|c|c|}
\hline $\begin{array}{c}\text { Number of } \\
\text { iteration } \mathbf{i}\end{array}$ & $|\mathbf{F}(\mathbf{Z})|$ & $\begin{array}{c}\text { Number of } \\
\text { iteration } \mathbf{i}\end{array}$ & $|\mathbf{F}(\mathbf{Z})|$ \\
\hline 61 & 0.4235 & 69 & 0.4237 \\
\hline 62 & 0.4236 & 70 & 0.4237 \\
\hline 63 & 0.4236 & 71 & 0.4237 \\
\hline 64 & 0.4236 & 72 & 0.4237 \\
\hline 65 & 0.4233 & 73 & 0.4237 \\
\hline 66 & 0.4234 & 74 & 0.4238 \\
\hline 67 & 0.4237 & 75 & 0.4238 \\
\hline 68 & 0.4237 & 76 & 0.4238 \\
\hline
\end{tabular}

Here we skipped 60 iterations and observed that the value converges to a fixed points after 73 iterations. 
Fig.13 : Orbit of $F(z)$ at $s^{\prime}=0.1$ and $s^{\prime}=0.5$ for $(\mathrm{z0}=$ $0.3934870291+0 \mathrm{i})$

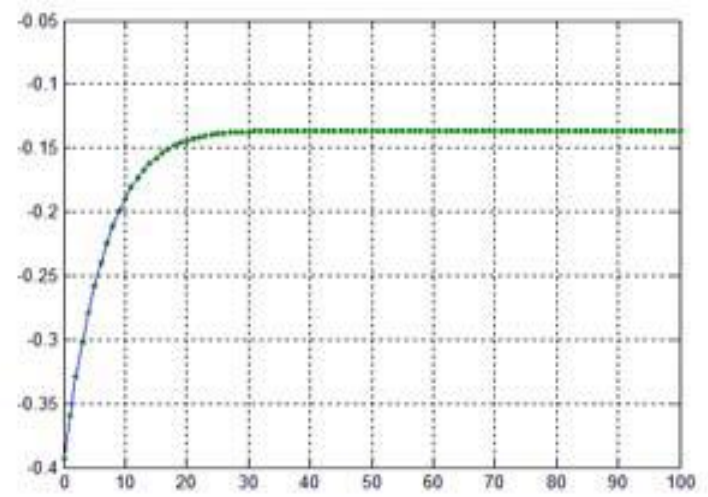

Table 2. Fixed points of Sine Cubic polynomial, Orbit of $\mathrm{F}(\mathrm{z})$ at $\mathrm{s}^{\prime}=0.1$ and $\mathrm{s}^{\prime}=0.5$ for $(\mathrm{z0}=0.07944042258+$ $0.03670696339 i$ )

\begin{tabular}{|c|c|c|c|}
\hline $\begin{array}{c}\text { Number of } \\
\text { iteration i }\end{array}$ & $|\mathbf{F}(\mathbf{Z})|$ & $\begin{array}{c}\text { Number of } \\
\text { iteration } \mathbf{i}\end{array}$ & $|\mathbf{F}(\mathbf{Z})|$ \\
\hline 51 & 0.4161 & 58 & 0.4163 \\
\hline 52 & 0.4162 & 59 & 0.4163 \\
\hline 53 & 0.4162 & 60 & 0.4163 \\
\hline 54 & 0.4162 & 61 & 0.4163 \\
\hline 55 & 0.4163 & 62 & 0.4164 \\
\hline 56 & 0.4163 & 63 & 0.4164 \\
\hline 57 & 0.4163 & 64 & 0.4164 \\
\hline
\end{tabular}

Here we skipped 50 iterations and observed that the value converges to a fixed points after 61 iterations.

Fig.14 : Orbit of $\mathrm{F}(\mathrm{z})$ at $\mathrm{s}^{-0.1}$ and $\mathrm{s}^{\prime}=0.5$ for $(\mathrm{z0}=$ $0.07944042258+0.03670696339 i)$

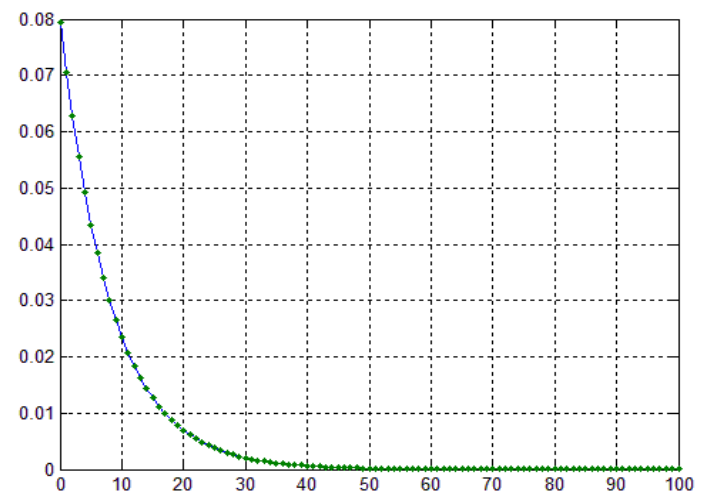

Table 3. Fixed points of Tangent quadratic polynomial, Orbit of $F(z)$ at $s^{\prime}=0.6$ and $s^{\prime}=0.3$ for $(\mathrm{z0}=-$ $0.61455061980+0.00900541716 i)$

\begin{tabular}{|c|c|c|c|}
\hline $\begin{array}{c}\text { Number of } \\
\text { iteration i }\end{array}$ & $|\mathbf{F}(\mathbf{Z})|$ & $\begin{array}{c}\text { Number of } \\
\text { iteration } \mathbf{i}\end{array}$ & $|\mathbf{F}(\mathbf{Z})|$ \\
\hline 1 & 0.6146 & 9 & 0.4168 \\
\hline 2 & 0.3143 & 10 & 0.4169 \\
\hline 3 & 0.3667 & 11 & 0.4169 \\
\hline 4 & 0.4072 & 12 & 0.4169 \\
\hline 5 & 0.4185 & 13 & 0.4169 \\
\hline 6 & 0.4186 & 14 & 0.4169 \\
\hline 7 & 0.4174 & 15 & 0.4169 \\
\hline 8 & 0.4169 & 16 & 0.4169 \\
\hline
\end{tabular}

Here we observed that the value converges to a fixed point after 9 iterations.

Fig.15 : Orbit of $F(z)$ at at $s=0.6$ and $s^{\prime}=0.3$ for $(\mathrm{z0}=-$ $0.61455061980+0.00900541716 i)$

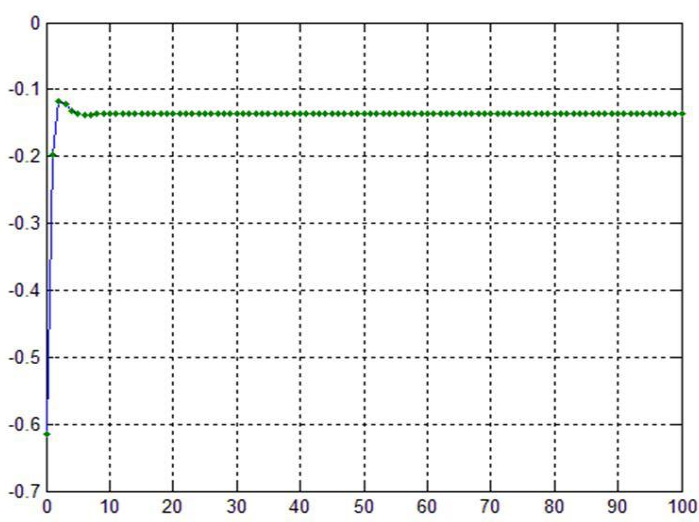

Table 4. Fixed points of Tangent Cubic polynomial, Orbit Orbit of $F(z)$ at $s^{\prime}=0.9$ and $s^{\prime}=0.1$ for $(\mathrm{z} 0=-0.03352184239$ 0.03135431148 i)

\begin{tabular}{|c|c|c|c|}
\hline $\begin{array}{c}\text { Number of } \\
\text { iteration } \mathbf{i}\end{array}$ & $|\mathbf{F}(\mathbf{Z})|$ & $\begin{array}{c}\text { Number of } \\
\text { iteration i }\end{array}$ & $|\mathbf{F}(\mathbf{Z})|$ \\
\hline 1 & 0.0459 & 7 & 0.4237 \\
\hline 2 & 0.4469 & 8 & 0.4238 \\
\hline 3 & 0.4161 & 9 & 0.4238 \\
\hline 4 & 0.4261 & 10 & 0.4238 \\
\hline 5 & 0.4230 & 11 & 0.4238 \\
\hline 6 & 0.4230 & 12 & 0.4238 \\
\hline
\end{tabular}

Here we observed that the value converges to a fixed point after 7 iterations. 
Fig.16 : Orbit of $F(z)$ at $s=0.9$ and $s^{\prime}=0.1$ for $(z 0=-$ 0.03352184239-0.03135431148 i)

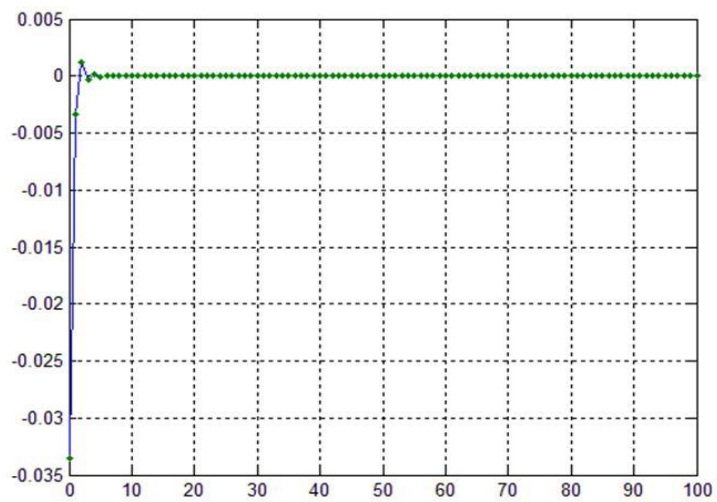

\section{CONCLUSION}

In this paper we studied the generation of fractal geometries using the two functions: the sine function and the inverse tangent function. Both the functions belong to same class of function families known as transcendental family. For Sine function, the fixed point 0 for $\mathrm{S}(\mathrm{z})=\operatorname{Sin} \mathrm{z}$ also satisfies $S^{\prime}(0)=1$. The orbit on the real axis tends to zero and the orbit on the imaginary axis tends to infinity, in case of sine function. For inverse tangent function, the relative superior Julia set possesses $n+1$ wing, whereas, in case of sine function this count is $2 \mathrm{n}$. We also observed in our results that for tangent function, in case of even powers, relative superior Mandelbrot sets are symmetrical only along the real axis, while on the other hand, for odd terms, body maintains its symmetry along both the axis. Also, in the past literature the Julia sets were shown to be disconnected, which in our research, were found to be connected for relative superior Ishikawa iterates.

\section{ACKNOWLEDGMENTS}

We express our thanks to Dr. A.K. Swami, Principal, G.B.Pant Engineering College, Ghurdauri, for providing necessary infrastructure for the research work. We would also like to thanks Dr. Priti Dimri, Head, Department of Computer Science and Applications, G.B.Pant Engineering College, Ghurdauri, for her unconditional and valuable support in writing this paper.

\section{REFERENCES}

[1] W. Bergweiler, Iteration of meromorphic functions. Bull. Amer. Math. Soc. (N. S.) 29 (1993), 151-188.

[2] W. Bergweiler and A Ereneko, "Dynamics of a higher dimensional analog of the trigonometric functions", Bull. Amer. Math. Soc. (N. S.)1 (2010), 35-38.

[3] B. Branner, The Mandelbrot Set, Proceedings of Symposia in Applied Mathematics39 (1989), 75-105. Published as Chaos and Fractals: The Mathematics Behind the Computer Graphics.

[4] Yashwant S Chauhan, Rajeshri Rana and Ashish Negi. "New Julia Sets of Ishikawa Iterates", International Journal of Computer Applications 7(13):34-42, October 2010. Published By Foundation of Computer Science.ISBN: 978-93-80746-97-5.

[5] R. L. Devaney and M. Krych, "Dynamics of $\exp (\mathrm{z})$ ", Ergodic Theory Dynam. Systems4 (1984), 35-52.
[6] R. L. Devaney and F. Tangerman, "Dynamics of entire functions near the essential Singularity", Ergodic Theory Dynam. Systems 6 (1986), 489-503.

[7] Robert L. Devaney, "An Introduction to Chaotic Dynamical Systems", Second Edition, 1989, Perseus Books Publishing, Reading, MA.

[8] Priti Dimri, Shashank Lingwal and Ashish Negi "A Relative Superior Julia Set and Relative Superior Tricorn and Multicorns of Fractals" International Journal of Computer Application (0975-8887), Volume 43- No.6, April 2012, (ISBN : 973-93-80867-44-1).

[9] A Ereneko, "Iteration of entire functions", Dynamical Systems and Ergodic theory, Banach Center Publ. 23, Polish Sc. Pub. , Warsaw 1989, 339-345.

[10] Pierre Fatou, "Sur Iteration des functions transcendantes entires", Acta Math 47(1926), 337-378.

[11] S. Ishikawa, "Fixed points by a new iteration method", Proc. Amer. Math. Soc.44 (1974), 147-150.

[12] G. Julia, "Sur 1' iteration des functions rationnelles", J Math Pure Appli. 8 (1918), 737-747.

[13] Shashank Lingwal, Ashish Negi and Sumiti Kapoor "A Study of New Fractals Complex Dynamics for Inverse and Logarithmic Functions" International Journal of Computer Application (0975-8887), Volume 43- No.5, April 2012, (ISBN : 973-93-80867-43-3).

[14] B. B. Mandelbrot, " The Fractal Geometry of Nature", W. H. Freeman, New York, 1983.

[15] J. Milnor, "Dynamics in One Complex Variable: Third Edition”, Princeton University Press, 2006.

[16] Ashish Negi, Shashank Lingwal and Yashwant S. Chauhan "Complex and Inverse Complex Dynamics of Fractals using Ishikawa Iteration", International Journal of Computer Application (0975-8887), Volume 40No.12, February 2012, (ISBN : 978-93-80866-52-1).

[17] Rajeshri Rana and Yashwant Singh Chauhan "Escape Time Fractals of Inverse Tangent Function", International Journal of Computer \& Organization Trends, Volume 3, Issue 3 (2013), ISSN : 2249-2593.

[18] Rajeshri Rana, Yashwant Singh Chauhan and Ashish Negi "Generation of New Fractals for Sine Function", Int. J. Comp. Tech. Appl., Vol 2 (6), 1747-1754, ISSN : 2229-6093.

[19] Rajeshri Rana, Yashwant S Chauhan and Ashish Negi. "Ishikawa Iterates for Logarithmic Function", International Journal of Computer Applications 15(5):4756, February 2011. Published By Foundation of Computer Science. ISBN: 978-93-80747-50-1.

[20] Rajeshri Rana, Yashwant S Chauhan and Ashish Negi. "Non Linear Dynamics of Ishikawa Iteration", International Journal of Computer Applications 7(13):43-49, October 2010. Published By Foundation of Computer Science.ISBN: 978-93-80746-97-5.

[21] Dierk Schleicher and Johannes Zimmer, "Escaping Points of Exponential Maps", Journal of the London Mathematical Society (2) 67(2003), 380-400. 